\title{
ANALISIS QOS DENGAN VIRTUAL TENANT NETWORK PADA SOFTWARE DEFINE NETWORKING
}

\author{
Rakhmat Purnomo ${ }^{1}$, \\ Teknik Informatika \\ Universitas Bhayangkara Jakarta Raya \\ rakhmat.purnomo@dsn.ubharajaya.ac.id
}

\author{
Prilly Rizky Arisandi \\ Teknik Informatika \\ Universitas Bhayangkara Jakarta Raya \\ prilly@gmail.com
}

\begin{abstract}
The purpose of this study is to analyze the application of the Virtual Tenant Network function in OpenDaylight in the Software-Define Networking technology architecture. The main problem in building computer network infrastructure is that it is very dependent on network device vendors. The price of network devices is also relatively expensive and the compatibility of each device is also part of the problem that needs a solution. Open-source Software-Define Networking technology allows network infrastructure developers not to depend on network device vendors. The research method uses simulation. The service quality indicators (Quality of Services) tested include delay, jitter, throughput, and packet lost. The results of the study show that the quality of service is in the good category because the value is above the standard set by the International Telecommunication Union (ITU-T).
\end{abstract}

Keywords : QoS, Virtual Tenant Network, SDN

\section{PENDAHULUAN}

Sudah lebih dari 47 tahun internet digunakan untuk menghubungkan perangkat jaringan guna berkomunikasi dan berbagi informasi (Comer, 2009). Setiap tahun lebih dari 1 juta orang terhubung ke internet. Lahirnya teknologi Internet of Things (IoT) yang menyediakan konektifitas dan pengelolaan jarak jauh ke hampir semua perangkat melalui internet mengakibatkan peningkatan lalu lintas data (Zimmermann et al., 2015). Data ini dibagi menjadi 2 yaitu kontrol lalu lintas data dan data itu sendiri. Mengkonfigurasi router dan switch secara konvensional menjadi masalah yang kompleks. Dasar inilah yang mendorong untuk melakukan inovasi dalam mengelola perangkat jaringan.

Software-define Networking (SDN) merupakan pendekatan baru dalam bidang jaringan komputer yang merubah arsitektur perangkat jaringan seperti saklar dengan menyederhanakan struktur node yang kompleks (Ummah \& Abdillah, 2016). SDN memberikan satu pengatur jaringan terpusat yang berbasis perangkat lunak dan dipisahkan dengan data nya.
Banyak Controller yang digunakan dalam SDN. Penelitian ini menggunakan Open Daylight.

Salah satu penelitian yang dilakukan (Ummah \& Abdillah, 2016) adalah dengan membangun simulasi jaringan virtual berbasis SDN. Tools yang digunakan Mininet. Skenario yang dibuat meliputi 2 switch, 4-switch, 8-switch, dan 16-switch. Hasil penelitiannya adalah simulasi jaringan virtual SDN telah bekerja dengan baik dengan parameter uji meliputi packet loss, delay, jitter, dan throughput.

Penelitian yang dilakukan (Kaur, Singh, \& Ghumman, 2014) menunjukan emulator yang paling banyak digunakan untuk membangun SDN adalah mininet. Dengan mininet, pembuatan prorotype jairngan berskala besar secara mudah dilakukan seperti membuat virtual host, switch controller, dan link. Mininet mendukung untuk penelitian, pengembangan eksperimen, pembelajaran, prototyping, pengetesan, pencarian kesalahan, dan masih banyak pengembangan eksperimen yang bisa dilakukan di mininet dengan hanya menggunakan PC atau laptop.

Penelitian yang dilakukan oleh (Zoher Bholebawa \& Dalal, 2016) membandingkan kinerja antara topologi bawaan pada mininet yaitu topologi linier, single, dan tree. Penelitian ini melakukan pengujian bandwidth pada setiap topologi yang kemudian dibandingkan. Hasil penelitian ini menunjukan topologi tree lebih baik dibandingkan dengan topologi lainnya.

Penelitian yang dilakukan (Asadollahi, Goswami, \& Gonsai, 2017) menggunakan OpenDaylight sebagai kontroler. Penelitiannya membahas tahapan dalam penerapan kontroler Opendaylight dalam SDN. Versi yang digunakan adalah Beryllium-SR4 yang dirilis pada 26 Oktober 2016.

Berdasarkan kajian penelitian sebelumnya yang berkaitan dengan SDN, perlu di analisis salah satu fitur yang ada di SDN yaitu Virtual Tenant Network (VTN). Penerapan VTN pada SDN akan disesuaikan dengan topologi jaringan yang ada di Universitas Bhayangkara Jaya. 


\section{A. OpenDaylight}

OpenDaylight merupakan sebuah kontroler SDN yang berlisensi terbuka atau opensource dan menggunakan bahasa pemrograman Java dan dikelola Linux Foundation dan didukung oleh lebih dari 40 perusahaan seperti IBM, Cisco, Juniper, VMWare, dan sejumlah vendor jaringan besar (Asadollahi et al., 2017).

Dalam website resminya, OpenDaylight Foundation selaku perusahaan yang mempromosikan OpenDaylight Platform menyatakan bahwa OpenDaylight (ODL) merupakan sebuah platform SDN terbuka untuk segala ukuran dan skalabilitas jaringan. ODL mengaktifkan layanan jaringan melalui sebuah spectrum perangkat keras dalam banyak vendor. Arsitekturnya membuat pengguna dapat mengendalikan aplikasi, protokol, dan berbagai macam plugin. ODL juga menyediakan koneksi antara pemakai luar dan penyedia layanan. Pengembangan ODL di kerjakan oleh sebuah komunitas yang besar yang memperbarui platform tersebut kurang lebih setiap enam bulan dan secara terus menerus dan menyesuaikan untuk mendukung rangkaian kasus penggunaan SDN dan Network Funtions Virtualization (NFV) yang paling luas di industri.

OpenDaylight memiliki banyak fitur atau plugin yang mudah untuk diaktifkan dan dinonaktifkan. Diantaranya ialah:

- AAA

- ALTO

- Border Gateway Protocol

- Border Gateway Monitoring Protocol (BMP)

- Control and Provisioning of Wireless Access Points (CAPWAP)

- Controller Shield

- Device Identification and Driver Management (DIDM)

- DLUX

- Fabric as a Service (FaaS)

- Group Based Policy

- Internet of Things Data Management

- Link Aggregation Control Protocol (LACP)

- Location Identifier Separation Protocol (LISP) Flow Mapping Service (LISP)

- NEMO

- NETCONF

- NetIDE

- OVSDB-based Network Virtualization Services

- OpenFlow plugin

- Path Computation Element Protocol (PCEP)

- Secure Network Bootstraping Interface (SNBi)
- Service Function Chaingin (SFC)

- SNMP Plugin

- SNMP4SDN

- Source-Group Tag Exchange Protocol (SXP)

- Topology Processing Framework

- Time Series Data Repository (TSDR)

- Unified Secure Channel

- Virtual Tenant Network (VTN)

\section{B. Virtual Tenant Network}

Virtual Tenant Network (VTN) merupakan salah satu fitur dari OpenDaylight (Shin, Kang, Kwak, Lee, \& Yang, 2014). VTN ini merupakan sebuah aplikasi yang menyediakan berbagai macam jaringan tenant pada sebuah kontroler SDN. Keunikan dari VTN ini ialah abstraksi secara logika. Yang membuat pemisahan antara topologi secara logika dan topologi secara fisik. VTN juga dapat mendefinisikan jaringan yang terlihat seperti jaringan konvensional L2/L3. Ketika jaringan didesain pada VTN, maka akan secara otomatis di mapping ke dalam jaringan fisik dan kemudian dikonfigurasikan pada setiap switch yang terhubung dengan kontroler SDN. Pendefinisian dari logical plane tidak hanya memungkinkan disembunyikannya kompleksitas jaringan tapi juga dapat lebih baik dalam memanajemen sumber daya jaringan. Hal ini akan mengurangi waktu pengkonfigurasian ulang layanan jaringan dan meminimalkan eror dalam konfigurasi. Ada dua komponen dari VTN yaitu VTN Manager dan VTN Coordinator. VTN manager adalah fitur yang berinteraksi dengan modul lain untuk mengimplementasikan model komponen VTN. VTN Manager juga menyediakan antarmuka REST API untuk mengkonfigurasi komponen VTN di OpenDaylight. Diantaranya membuat, memperbarui, dan menghapus komponen VTN. Untuk mengaktifkan fitur ini memerlukan plugin odl-vtn-manager dan odl-vtn-manager-rest.

\section{METODOLOGI}

\section{A. Objek Penelitian}

Metode penelitian dengan melakukan simulasi penerapan arsitektur Software-Defined Networking dengan protokol OpenFlow pada Universitas Bhayangkara Jakarta Raya beserta analisis kinerja jaringan Universitas Bhayangkara Jakarta Raya (UBJ) dan kinerja Arsitektur Software-Defined Networking. Gambar 1 menunjukan tahapan penelitian yang dilakukan. 


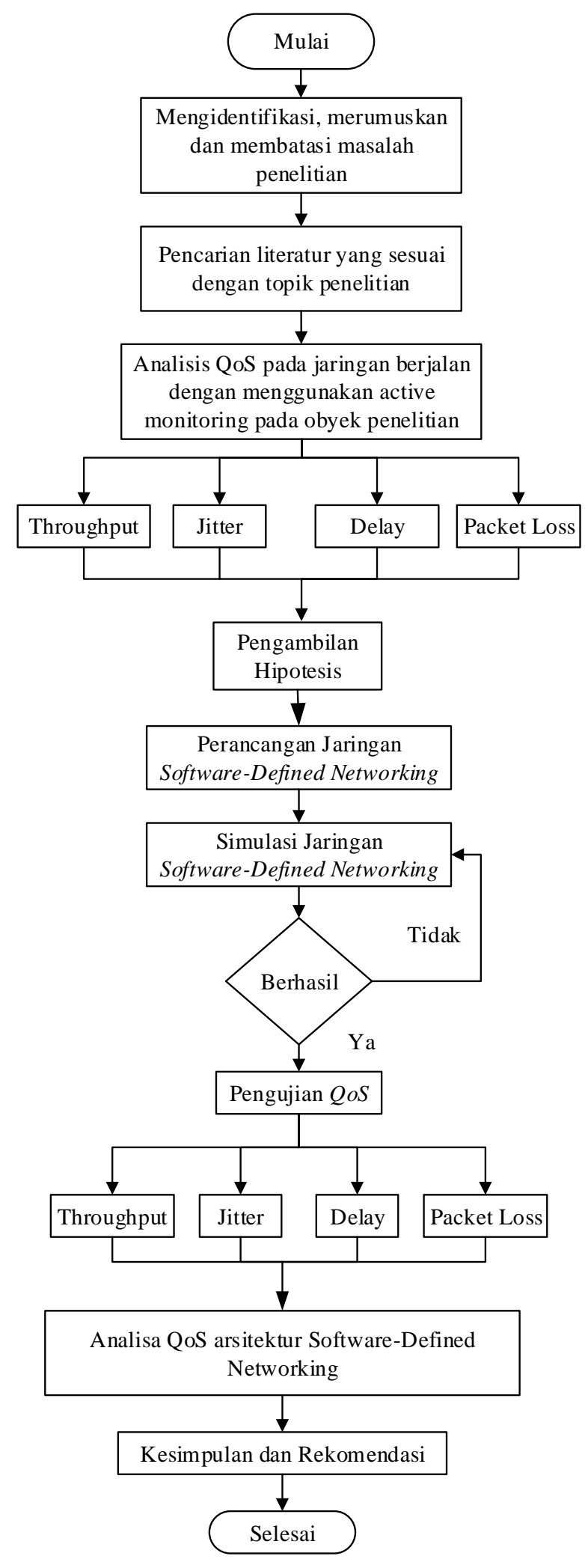

Gambar 1. Tahapan Penelitian

Langkah - langkah dalam alur penelitiannya yaitu dimulai dari pengidentifikasian masalah dengan melakukan wawancara dan observasi pada tempat penelitian. Observasi dilakukan dengan melakukan percobaan kualitas layanan jaringan. Hasil dari observasi berupa gambar topologi jaringan pada UBJ yang masih menggunakan jaringan konvensional.

Kemudian peneliti melakukan kajian pustaka untuk mencari teori pendukung berdasarkan topik yang dikaji. Tahap berikutnya adalah melakukan active monitoring untuk mengetahui seberapa besar kualitas layanannya.

Berikutnya dilakukan perancangan usulan skema jaringan yang akan dibuat. Topologi yang dibuat sudah menggunakan arsitektur berbasis SDN. Rancangan ini kemudian diterapkan pada simulasi menggunakan komputer. Selanjutnya pengujian dilakukan dengan parameter throughput, jitter, delay dan packet loss. Hasilnya dibandinkan dengan arsitektur jaringan konvensional.

\section{B. Peralatan penelitian}

Peralatan hardware yang digunakan untuk membangun simulasi SDN dapat dilihat dari Tabel 1 berikut :

Tabel 1. Peralatan Penelitian

\begin{tabular}{|c|c|c|}
\hline Spek & Mininet & Controller \\
\hline Prosesor & $\begin{array}{l}\text { Intel }{ }^{\circledR} \text { Core }^{\mathrm{TM}} \\
\mathrm{I} 3 \mathrm{CPU} 3.3 \mathrm{GHz}\end{array}$ & $\begin{array}{l}\text { Intel } \AA \text { Core }^{\mathrm{TM}} \\
\mathrm{I} 3 \mathrm{CPU} 3.3 \mathrm{GHz}\end{array}$ \\
\hline RAM & $4 \mathrm{~GB}$ & 4 GB \\
\hline $\begin{array}{l}\text { Sistem } \\
\text { Operasi }\end{array}$ & $\begin{array}{l}\text { Ubuntu Desktop } \\
16.0464 \text { bit }\end{array}$ & $\begin{array}{l}\text { Ubuntu Server } \\
14.04 \text { LTS } 64 \\
\text { bit }\end{array}$ \\
\hline Fungsi & $\begin{array}{l}\text { Untuk simulasi } \\
\text { jaringan } \\
\text { Software- } \\
\text { Defined } \\
\text { Networking }\end{array}$ & $\begin{array}{l}\text { komputer untuk } \\
\text { kontroler } \\
\text { Software- } \\
\text { Defined } \\
\text { Networking }\end{array}$ \\
\hline
\end{tabular}

Sedangkan Perangkat Lunak yang digunakan antara lain :

1. OpenDaylight Boron 0.5.3 sebagai SDN Controller.

2. Mininet 2.2.1 sebagai emulator jaringan Software-Defined Networking.

Wireshark 2.0 sebagai program analisa paket data.

\section{HASIL DAN PEMBAHASAN}

\section{A. Perancangan Topologi Arsitektur} SDN

Topologi menggunakan arsitektur Software-Defined Networking, dalam penerapannya arsitektur ini menggunakan Switch OpenFlow sebagai data plane dan controller sebagai control plane. Topologi yang akan 
diterapkan yaitu dengan spesifikasi sebagai berikut:

1. Jumlah Switch OpenFlow : 4 buah

2. Controller : 1 buah

3. Jumlah Host : 68 buah

4. Jumlah link :71 link
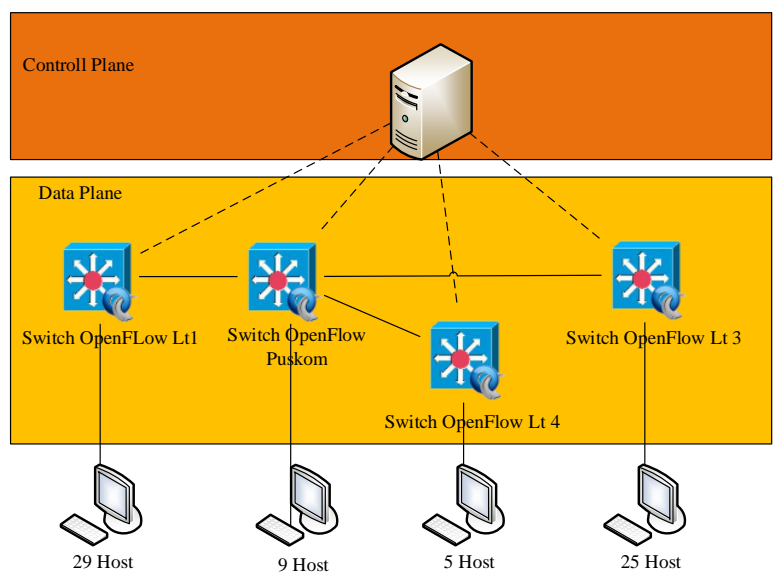

Gambar 2. Topologi Skema Arsitektur SDN

\section{B. Topologi Simulasi}

Implementasi jaringan dengan arsitektur Software-Defined Networking (SDN) ini menggunakan metode simulasi. Jadi studi kasus penerapan arsitektur SDN ini menggunakan metode simulasi.

Skenario simulasi jaringan terlihat pada gambar 3.

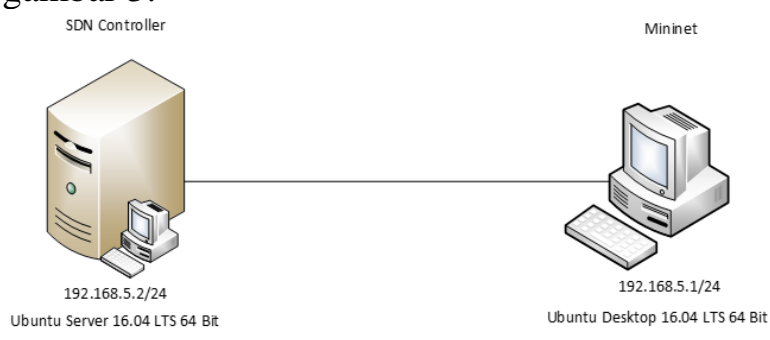

Gambar 3. Skema Simulasi Jaringan

\section{Konfigurasi OpenDaylight}

Tahapan instal dan konfigurasi OpenDaylight diawalai dengan menentukan versi yang akan digunakan yaitu Boron versi 0.5.3 yang diinstal pada sistem operasi Ubuntu Server Desktop LTS 16.04. OpenDaylight ini menggunakan fitur kafar untuk menjalankan Opendaylight tanpa harus instalasi. Fitur kafar OpenDaylight dapat kapan saja dijalankan maupun dihentikan programnya.

\section{Tahap 1 : Persiapan}

Unduh OpenDaylight Boron-SR3. Langkah-langkah unduh pada website OpenDaylight adalah sebagai berikut :
1) Ketik url http://www.opendaylight.org/start pada browser. Terdapat banyak versi yang disediakan oleh OpenDaylight. Peneliti menggunakan versi Boron-SR3.

2) Kemudian klik Pre-BuiltZip.

3) Unggah berkas OpenDaylight tersebut ke server kontroler menggunakan aplikasi ftp client. Disini peneliti menggunakan WinSCP FTP Client. Selanjutnya buka aplikasi WinSCP tersebut.

4) Isi Hostname yaitu IP Address dari server kontroler dan Username serta password. Proses autentikasi server berlangsung. Kemudian pada aplikasi WinSCP cari file OpenDayligh yang telah terunduh.

5) Ungga ke dalam server kontroler

6) Setelah OpenDaylight berhasil terunggah. Selanjutnya ekstrak file zip OpenDaylight tersebut. Caranya ketikan perintah pada console. Proses ini dilakukan pada server kontroler.

unzip distribution-karaf-0.5.3-Boron-SR3.zip

7) Selanjutnya install Java JDK versi 8 yang mendukung versi OpenDaylight tersebut. apt-get install aracle-java-

8) Kemudian konfigurasi letak JAVA_HOME. export JAVA_HOME=/usr/lib/jvm/java-8-oracle

\section{Tahap 2. Menjalankan OpenDaylight}

Setelah mengunduh, mengekstrak OpenDaylight dan menyiapkan paket pendukung lainnya. Langkah selanjutnya adalah menjalankan OpenDaylight.

1) Caranya masuk ke dalam direktori OpenDaylight.

cd distribution-karaf-0.5.3-Вoгnn-SR3

2) Kemudian ketikkan perintah dibawah ini: bin/karaf clean -ofl3

3) Setelah berhasil menjalankan OpenDaylight selanjutnya masuk ke dalam console OpenDaylight.

\section{Tahap 3. Mengaktifkan fitur-fitur yang dibutuhkan}

Secara default setelah OpenDaylight dijalankan belum ada plugin atau fitur yang aktif. Fitur atau plugin tersebut diaktifkan secara manual. Pada penelitian ini fitur OpenDaylight yang akan diaktifkan adalah dlux, l2switch dan vtn-manager.

Caranya ketik pada console OpenDaylight : feature:install odl-dlux-all odl-12switch-switch-ui odl-vtn-manager odl-vtn-manager-rest

OpenDaylight telah siap digunakan langkah selanjutnya akses Kontroler SDN melalui browser 
dengan mengakses

\section{http://192.168.5.2:8181/index.html}

\section{Konfigurasi Mininet}

Mininet merupakan sebuah emulator yang bisa mensimulasikan jaringan dengan arsitektur jaringan berbasis Software-Defined Networking yang bisa menciptakan host seperti nyatanya, dan komponen perangkat jaringan lainnya seperti Open vSwitch yang mendukung Switch Openflow (Pambudi \& Wibowo, 2015). Dengan mininet ini kita bisa mempunyai arsitektur jaringan seprti aslinya. Proses ini dilakukan pada PC client yang akan dijadikan tempat untuk mininet.

\section{Tahap 1. Persiapan}

Untuk memulai pengunduhan mininet dari sumber utama, langkah - langkahnya sebagai berikut :

1) ketik command dibawah berikut pada terminal

git clone git://github.com/mininet/mininet

2) Selanjutnya masuk ke dalam direktori mininet. Dengan mengetikan:

cd mininet

3) Kemudian cek versi mininet yang tersedia. git tag

4) Setelah itu kita keluar dari direktori mininet. Dan kita jalankan perintah installasi mininet. mininet/util/install.sh -a

5) Setelah berhasil terinstall mininet siap dijalankan.

\section{Tahap 2. Menjalankan Mininet}

Setelah melakukan proses installasi mininet dan sebelum menjalankan mininet, peneliti membuat script yang telah menyesuaikan topologi jaringan UBJ. Script tersebut digunakan untuk menyesuakan topologi yang digunakan. Tahap selanjutnya adalah menjalankan script mininet tersebut.

mn -topo mytopo -custom=topo_ubj.py -controller remote,ip=192.168.5.2 -switch ovsk,protocols=】penFlowl3

Setelah mininet dijalankan maka akan tampil semua host dan switch berdasarkan yang telah dibuat dalam script mininet.

\section{Konfigurasi Virtual Tenant Network}

Peneliti menerapkan Virtual Tenant Network yaitu pada Switch OpenFlow LT1 dengan switch OpenFlow LT4. Peneliti mencoba membuat topologi virtual. Sehingga kedua host antara sisi switch OpenFlow LT1 dengan host di switch OpenFlow LT4 akan terhubung langsung secara logika. Konfigurasi ini dilakukan setelah OpenDaylight dan mininet dijalankan.

Langkah-langkah konfigurasi VTN adalah sebagai berikut:

1. Pertama buat sebuah vtn. Langkah konfigurasi VTN ini menggunakan vtn manager pada OpenDaylight.

2. Selanjutnya buat virtual bridge pada VTN.

3. Kemudian buat 2 buah virtual interface pada virtual bridge dengan nama port1 dan port2.

4. Langkah terakhir adalah mapping port fisik dari Open vSwitch pada mininet ke virtual interface pada virtual bridge

Setelah semua konfigurasi selesai dilakukan selanjutnya verifikasi bahwa VTN telah dibuat. Caranya adalah dengan mengakses link

http://192.168.5.2:8181/restconf/operation/vtn: vtns pada web browser.

Setelah itu pilih dan klik Show/Hide, selanjutnya klik Try it out maka akan ditampilkan konfigurasi VTN yang telah dibuat.

\section{E. Pengujian dan Analisis}

Pengujian dilakukan dengan 2 skenario yaitu yang pertama tanpa menggunakan VTN dan yang kedua dengan menggunakan VTN.

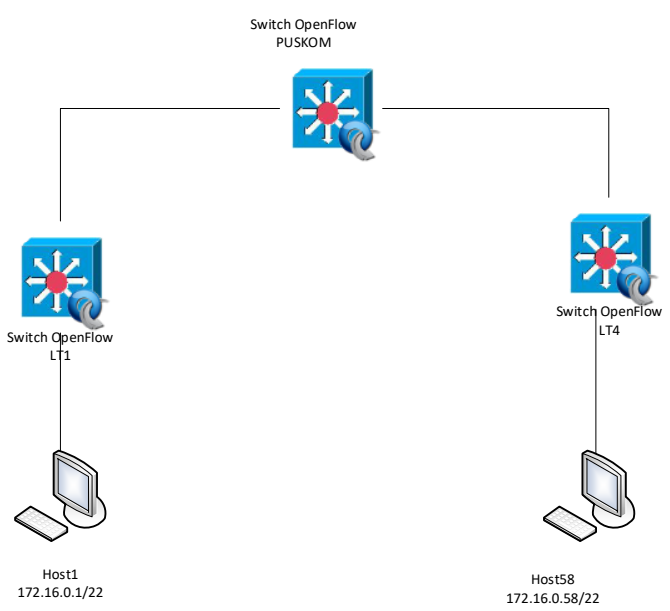

Gambar 4 Skenario Pengujian Arsitektur SDN

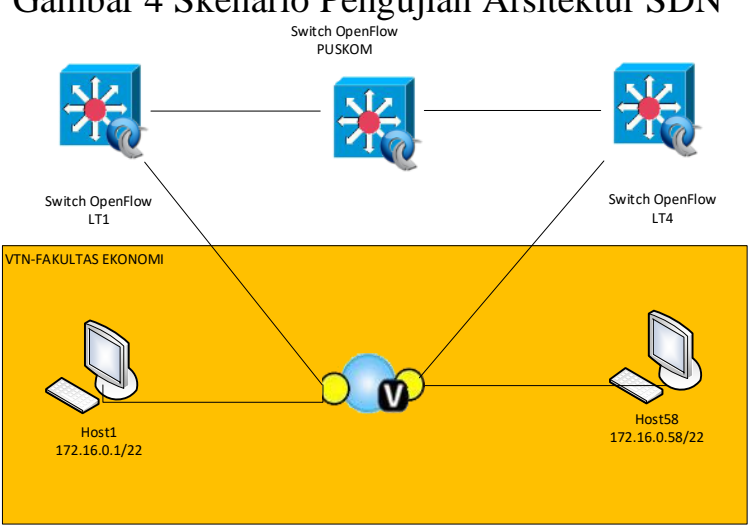

Gambar 5 Skenario Pengujian Arsitektur SDN dengan VTN 
Pengujian kualitas layanan jaringan pada arsitektur Software-Defined Networking dengan parameter throughput, delay, jitter dan packet loss dengan skema penerapan VTN dan non VTN.

\section{Pengujian Throughput}

Pada pengujian throughput peneliti menggunakan tools iperf yang merupakan tool yang sudah disediakan di dalam mininet. Pada pengujian throughput ini peneliti melakukan iperf dari host 1 ke host58 untuk mengatahui nilai throughput yang dihasilkan. Untuk proses pengujian bisa dilihat pada gambar 6 dan gambar 7.

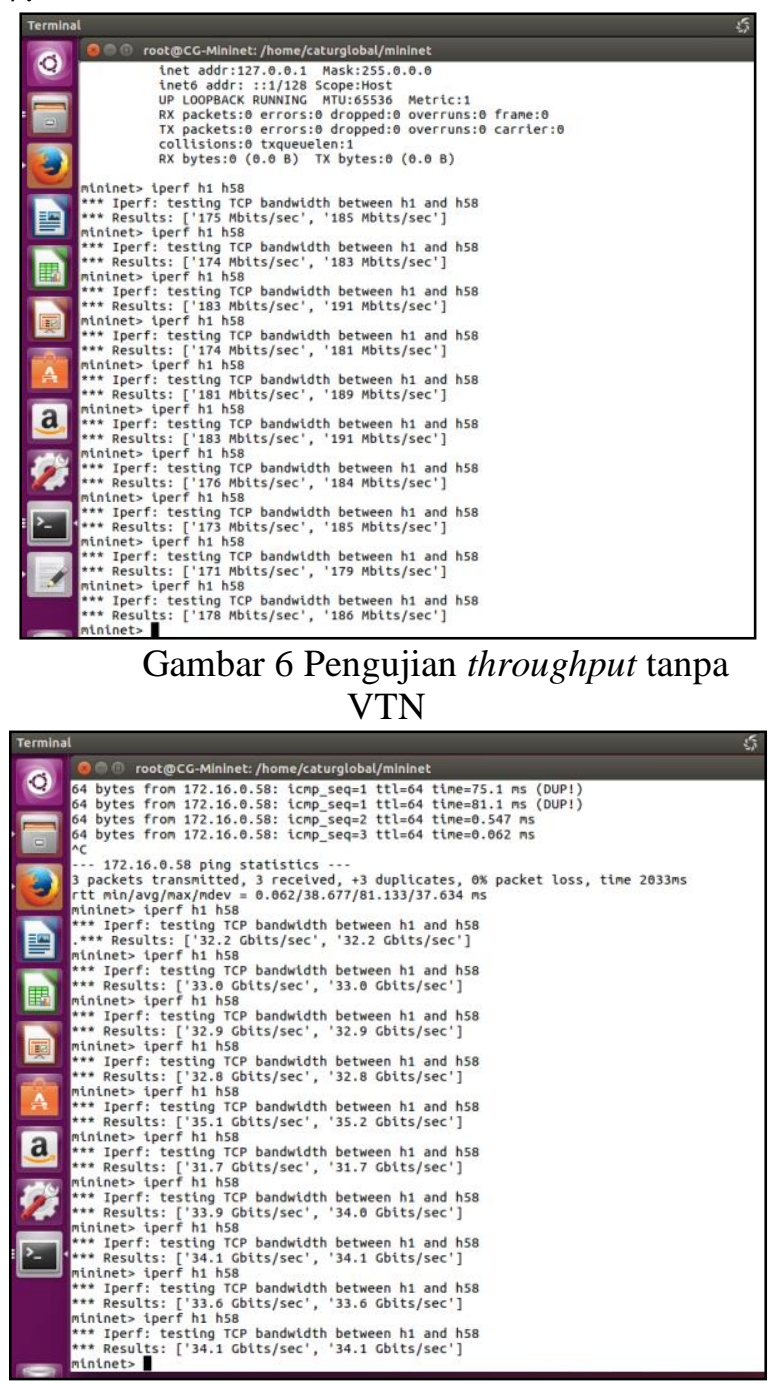

Gambar 7 Pengujian throughput dengan VTN
Tabel 2. Perbandingan nilai throughput yang menerapkan VTN dan yang tidak menerapkan VTN

\begin{tabular}{|l|r|r|r|}
\hline \multirow{2}{*}{$\begin{array}{c}\text { Nomer } \\
\text { Per } \\
\text { cobaan }\end{array}$} & $\begin{array}{c}|c| \\
\text { Konvensional } \\
\text { (Mbits/sec) }\end{array}$ & $\begin{array}{c}\text { Non } \\
\text { VTN } \\
\text { (Mbits/ } \\
\text { sec) }\end{array}$ & $\begin{array}{c}\text { VTN } \\
\text { (Gbits/s } \\
\text { ec) }\end{array}$ \\
\hline P 1 & 29.47 & 175 & 32.2 \\
\hline P 2 & 47.51 & 174 & 33 \\
\hline P 3 & 65.93 & 183 & 32.9 \\
\hline P 4 & 76.25 & 174 & 32.8 \\
\hline P 5 & 86.8 & 181 & 35.1 \\
\hline P 6 & 92.19 & 183 & 31.7 \\
\hline P 7 & 91.31 & 176 & 33.9 \\
\hline P 8 & 92.01 & 173 & 34.1 \\
\hline P 9 & 91.28 & 171 & 33.6 \\
\hline P 10 & 95.25 & 178 & 34.1 \\
\hline Rata- & 76.8 & 176.8 & 33.34 \\
\hline Rata & & & \\
\hline
\end{tabular}

Dari tabel 2 dapat dianalisis bahwa jaringan SDN dengan skenario pengujian menggunakan VTN mampu membawa bandwidth hingga Gbits/sec sedangkan tanpa VTN hanya bisa membawa bandwidth Mbits/sec.

\section{Pengujian Delay}

Peneliti melakukan uji ping dari hostl ke host58. Untuk mendapatkan nilai delay, dilihat pada waktu pengiriman dan waktu penerimaan paket dengan menggunakan aplikasi wireshark. Untuk hasil uji coba delay tanpa menerapkan VTN bisa dilihat pada tabel 3 dan untuk penerapan VTN bisa dilihat pada tabel 4. Peneliti memberikan sampel proses pengujian delay seperti pada gambar 8 untuk non VTN dan gambar 9 untuk penerapan VTN.

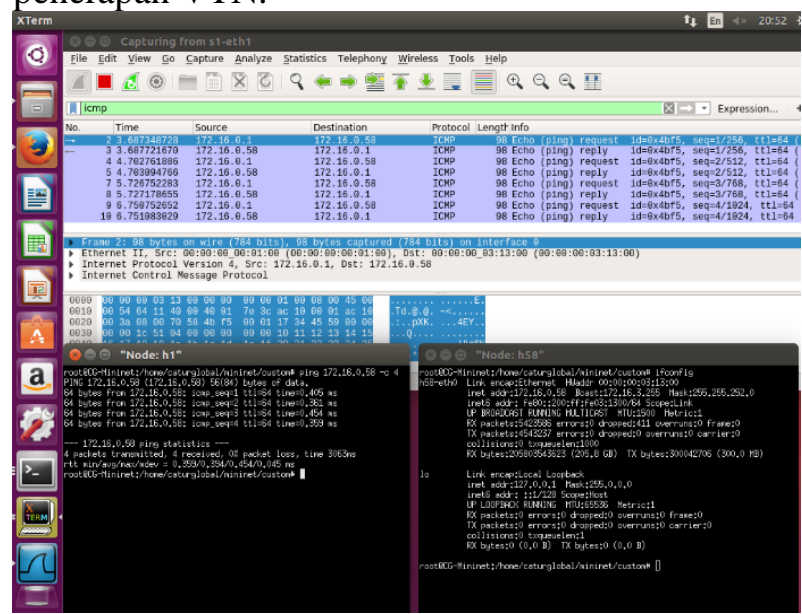

Gambar 8. Proses pengujian delay pada non VTN 


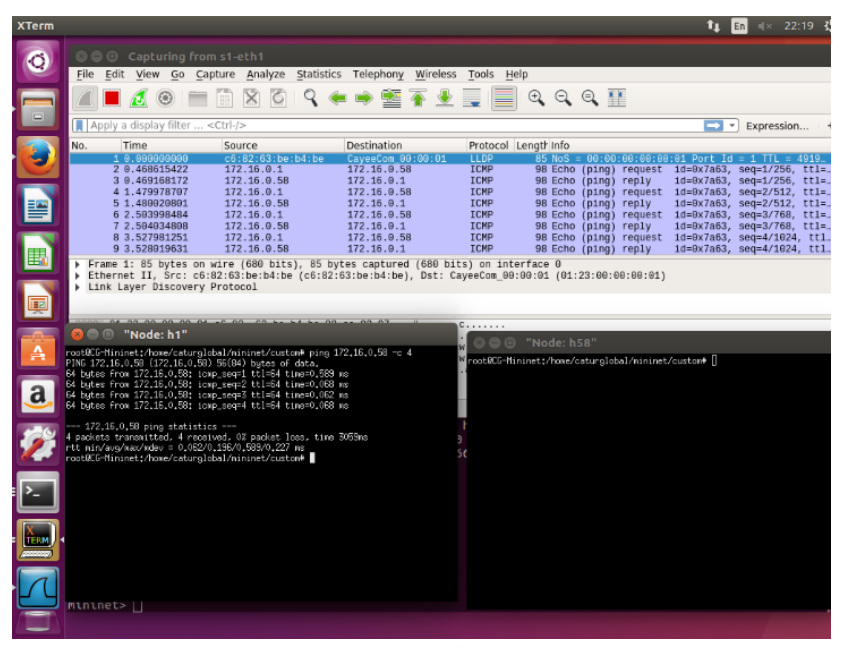

Gambar 9 Proses pengujian delay pada VTN

Tabel 3. Hasil pengujian delay tanpa menerapkan VTN

\begin{tabular}{|l|r|r|r|r|}
\hline $\begin{array}{c}\text { Nomer } \\
\text { Per } \\
\text { cobaan }\end{array}$ & Waktu Kirim (s) & $\begin{array}{c}\text { Waktu } \\
\text { Terima (s) }\end{array}$ & Delay (s) & Delay (ms) \\
\hline P 1 & 3.687348728 & 3.68772167 & 0.000373 & 0.372942 \\
\hline P 2 & 0 & 0.000864378 & 0.000864 & 0.864378 \\
\hline P 3 & 1.632311722 & 1.632815506 & 0.000504 & 0.503784 \\
\hline P 4 & 1.662460565 & 1.663448443 & 0.000988 & 0.987878 \\
\hline P 5 & 2.118494402 & 2.11950914 & 0.001015 & 1.014738 \\
\hline P 6 & 0.502089305 & 0.502782077 & 0.000693 & 0.692772 \\
\hline P 7 & 1.628222224 & 1.628999165 & 0.000777 & 0.776941 \\
\hline P 8 & 0.604353737 & 0.605275029 & 0.000921 & 0.921292 \\
\hline P 9 & 0 & 0.001374354 & 0.001374 & 1.374354 \\
\hline P 10 & 1.844277731 & 1.845407692 & 0.00113 & 1.129961 \\
\hline \multicolumn{5}{r}{ Rata-rata } \\
\hline
\end{tabular}

Tabel 4 Hasil pengujian delay dengan menerapkan VTN

\begin{tabular}{|l|r|r|r|r|}
\hline $\begin{array}{c}\text { Nomer } \\
\text { Per }\end{array}$ & $\begin{array}{c}\text { Waktu Kirim } \\
(\mathrm{s})\end{array}$ & $\begin{array}{c}\text { Waktu Terima } \\
(\mathrm{s})\end{array}$ & Delay (s) & Delay (ms) \\
\hline P 1 & 0.468615422 & 0.469168172 & 0.00055275 & 0.55275 \\
\hline P 2 & 0.2398074 & 0.240417311 & 0.000609911 & 0.609911 \\
\hline P 3 & 0 & 0.000550951 & 0.000550951 & 0.550951 \\
\hline P 4 & 4.391603886 & 4.391995865 & 0.000391979 & 0.391979 \\
\hline P 5 & 0 & 0.000572681 & 0.000572681 & 0.572681 \\
\hline P 6 & 0 & 0.000421018 & 0.000421018 & 0.421018 \\
\hline P 7 & 5.126731429 & 5.127309789 & 0.00057836 & 0.57836 \\
\hline P 8 & 0 & 0.000604257 & 0.000604257 & 0.604257 \\
\hline P 9 & 3.766665757 & 3.767080451 & 0.000414694 & 0.414694 \\
\hline P 10 & 0 & 0.000056941 & 0.000056941 & 0.056941 \\
\hline & \multicolumn{3}{|c|}{ Rata-rata } & 0.475354 \\
\hline
\end{tabular}




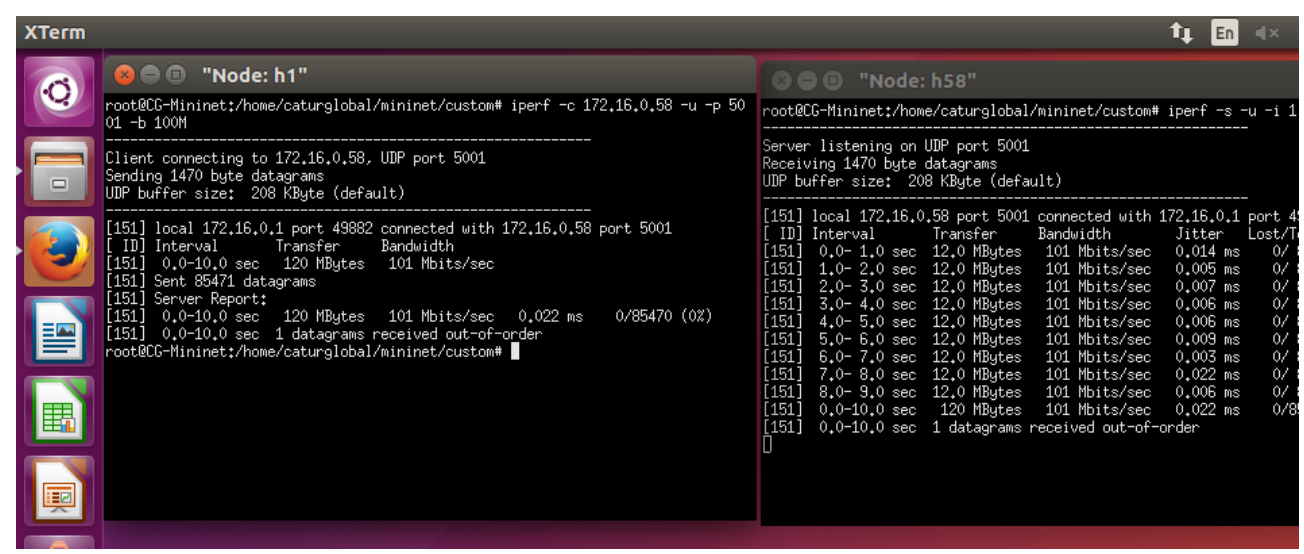

Gambar 10. Sampel proses uji coba jitter tanpa penerapan VTN

Berdasarkan tabel 3 dan tabel 4 dapat disimpulkan bahwa rata-rata delay pada penerapan VTN menghasilkan nilai yang lebih kecil dari non VTN. Meskipun begitu VTN dan non VTN sama-sama masih menghasilkan nilai diatas standar ITU-T.

\section{Pengujian Jitter}

Pengujian jitter dilakukan menggunakan iperf dengan protocol uji coba adalah protokol UDP dengan maksimal bandwidth 100Mbps. Untuk proses uji coba bisa dilihat pada gambar 10.

Setelah melakukan uji coba jitter maka didapatkan nilai jitter pada 10 kali percobaan yang tersusun pada tabel 5 .
Tabel 5. Hasil pengujian jitter pada SDN non VTN

\begin{tabular}{|c|c|}
\hline $\begin{array}{c}\text { Nomer } \\
\text { Percobaan }\end{array}$ & Nilai Jitter (ms) \\
\hline P 1 & 0.022 \\
\hline P 2 & 0.005 \\
\hline P 3 & 0.006 \\
\hline P 4 & 0.002 \\
\hline P 5 & 0.003 \\
\hline P 6 & 0.008 \\
\hline P 7 & 0.003 \\
\hline P 8 & 0.003 \\
\hline P 9 & 0.008 \\
\hline P 10 & 0.002 \\
\hline Rata-rata & 0.0062 \\
\hline
\end{tabular}

Selanjutnya pada gambar 11 menunjukan proses ujicoba jitter pada SDN yang menerapkan VTN

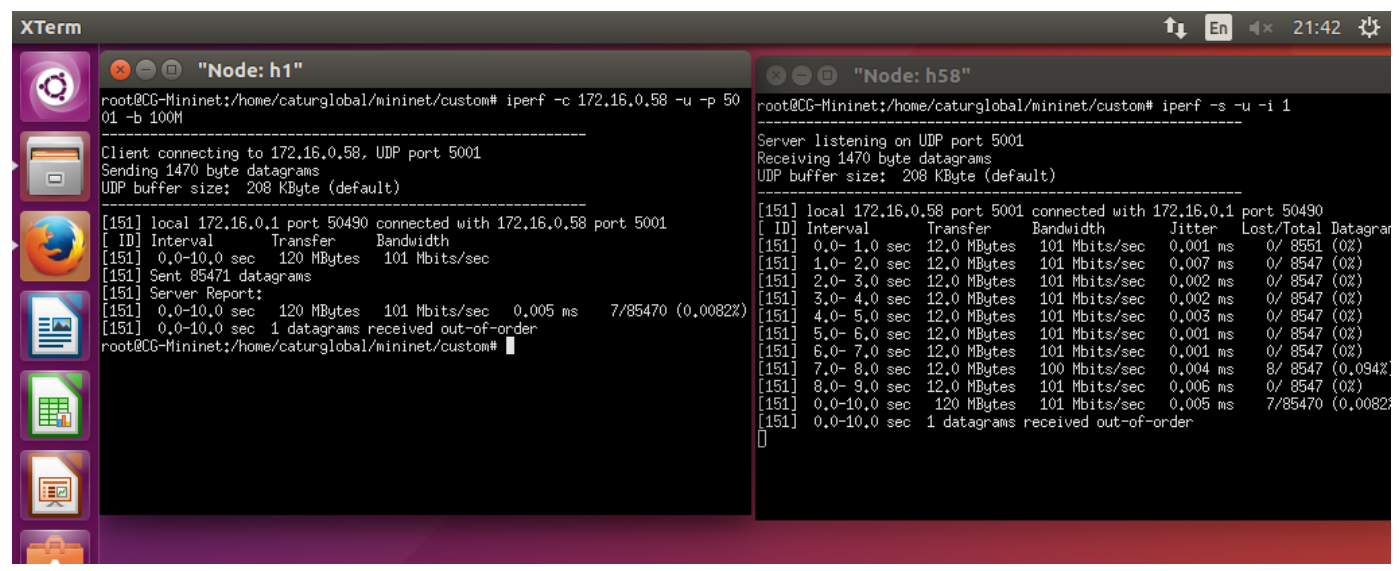

Gambar 11. Sampel proses uji coba jitter dengan penerapan VTN 
Tabel 6. Hasil pengujian jitter pada SDN VTN

\begin{tabular}{|c|c|}
\hline $\begin{array}{c}\text { Nomer } \\
\text { Percobaan }\end{array}$ & Nilai Jitter (ms) \\
\hline P 1 & 0.005 \\
\hline P 2 & 0.003 \\
\hline P 3 & 0.003 \\
\hline P 4 & 0.004 \\
\hline P 5 & 0.003 \\
\hline P 6 & 0 \\
\hline P 7 & 0.001 \\
\hline P 8 & 0.006 \\
\hline P 9 & 0.002 \\
\hline P 10 & 0.004 \\
\hline Rata-rata & 0.0062 \\
\hline
\end{tabular}

Dari tabel 6. dapat disimpulkan bahwa uji coba jitter pada arsitektur SDN yang menerapkan VTN menghasilkan nilai-nilai jitter yang lebih kecil dibandingkan yang tidak menerapkan SDN maupun pada jaringan konvensional. Namun hasil jitter tersebut sudah diatas standar bagus ITU-T.

\section{Pengujian Packet Loss}

Pengujian ini dilakukan percobaan ping dengan parameter count sebanyak 50. Nilai packet loss yang dihasilkan untuk kedua skenario adalah sama. Sehingga tidak ada perbedaan yang signifikan.

Gambar 12 menunjukan proses pengujian packet lost pada arsitektur SDN yang belum menerapkan VTN dimana dihasilkan $0 \%$ packet lost. Sedangkan gambar 13 menunjukan pengujian packet lost pada arsitektur SDN yang sudah menerapkan VTN.

Jika pengujian packet lost dilakukan pada dunia nyata maka akan didapat hasil yang signifikan karena banyak faktor yang mempengaruhinya

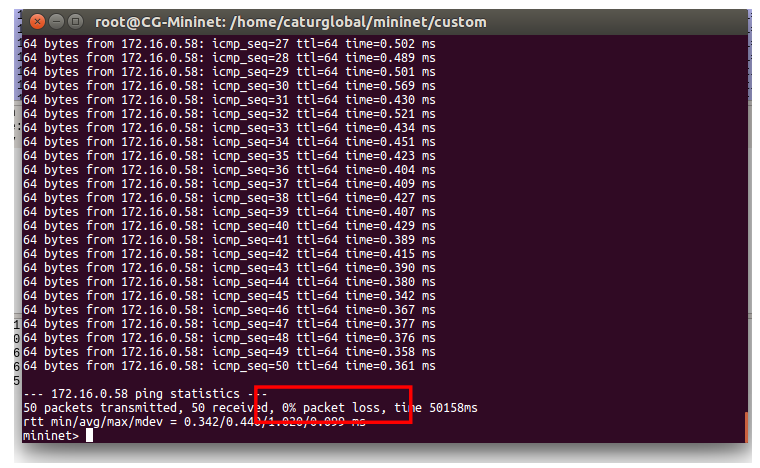

Gambar 12 Pengujian packet loss pada arsitektur SDN yang belum menerapkan VTN

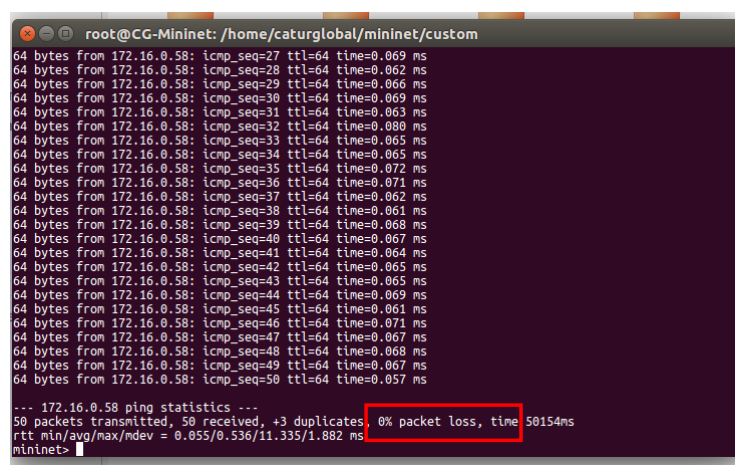

Gambar 13 Pengujian packet loss pada arsitektur SDN yang sudah menerapkan VTN

\section{KESIMPULAN}

Kesimpulan penelitian ini adalah terdapat peningkatan layangan QoS pada jaringan yang menggunakan arsitektur SDN dibandingkan jika menggunakan arsitektur konvensional, walaupun nilai keduanya masih diatas standar ITU-T. Pengujian throughput menghasilkan kemampuan arsitektur SDN dengan VTN mampu membawa bandwidth hingga Gbits/s sedangkan tanpa SDNVTN hanya bisa membawa bandwidth Mbits/sec. Pengujian delay menghasilkan nilai lebih kecil untuk arsitektur SDN-VTN dibandingkan dengan arsitektur konvensional tetapi tetap masih diatas standar ITU-T. Sedangkan pengujian packet loss tidak terdapat perbedaan signifikan.

\section{DAFTAR PUSTAKA}

Asadollahi, S., Goswami, B., \& Gonsai, A. M. (2017). Implementation of SDN using OpenDayLight Controller, 5(2), 218-227.

Comer, D. E. (2009). Computer Networks and Internets (Fifth). PEARSON Prentice Hall.

Kaur, K., Singh, J., \& Ghumman, N. S. (2014). Mininet as Software Defined Networking Testing Platform. International Conference on Communication, Computing \& Systems (ICCCS-2014), 3-6.

Pambudi, W., \& Wibowo, F. W. (2015). Uji Throughput Kontroler Floodlight dan Beacon Menggunakan Emulator Mininet. Universitas Gajah Mada.

Shin, Y. Y., Kang, S. H., Kwak, J. Y., Lee, B. Y., \& Yang, S. H. (2014). The Study on Configuration of Multi-Tenant Networks in SDN Controller. Electronics and Telecommunications Research Institute, 


$$
3(2), 16-19 .
$$

Ummah, I., \& Abdillah, D. (2016). Perancangan Simulasi Jaringan Virtual Berbasis Software-Define Networking. Jounal on Computing, 1(1), 95-106.

http://doi.org/10.21108/indojc.2016.1.1.20

Zimmermann, A., Schmidt, R., Sandkuhl, K., Wißotzki, M., Jugel, D., \& Möhring, M. (2015). Digital Enterprise Architecture Transformation for the Internet of Things -,
130-138.

http://doi.org/10.1109/EDOCW.2015.16

Zoher Bholebawa, I., \& Dalal, U. D. (2016).

Design and Performance Analysis of OpenFlow-Enabled Network Topologies Using Mininet. International Journal of Computer and Communication Engineering 5.6, 5(6), 419.

http://doi.org/10.17706/ijcce.2016.5.6.419429 